\title{
Religious Belonging and (Forced) Migration: a Study on Migrant Coptic Families in Italy
}

\author{
Cristina Giuliani and Camillo Regalia
}

\section{1 \\ (Forced) Migrants and Post-migration Processes}

Within the extant psychology scientific literature, the epidemiological and psychiatric perspectives for a long time have been predominant in research on (forced) migration processes. The latter approach aims at assessing the typology and severity of pre-migration traumas (including war-related violence, exposure to persecution for religious and/or political reasons, injustice and oppression) as well as their effects on the mental health of adult and under-age migrants (Hussain, Bhushan, 2009; Jović et al., 2005; McGregor et al., 2015; Reading, 2009; Wilson, Tang, 2007).

Recently, such theoretical models have become richer and more complex in two respects:

a) firstly, the focus has shifted from the pre-migration to the post-migration phase; this is characterized by numerous stressors related to resettlement and acculturative processes, which increase long-term risks of mental health issues (Betancourt et al., 2015; Laban et al., 2008);

b) secondly, the identification of risk factors and protective processes capable of moderating the link between cumulative trauma and psychosocial wellbeing has become richer.

Overall, although psychological/psychiatric diagnoses and comparisons are at times difficult, research on (forced) migrants, refugees and asylum seekers confirms the groups' high rates of psychological suffering, as well as increasing psychic pathologies in the post-migration phase. Indeed, this phase is likely characterized by a vicious cycle featuring the disruptive effects of traumas and difficulties prior to migration and of the multiple losses and stressors faced in the respective resettlement countries, ultimately leading to a shift from an "actual exile" condition to a "psychological exile condition" (Ellis et al., 2008; Jović et al., 2015; Salvatore et al., 2014).

As noted by a growing body of scientific literature featuring empirical studies mostly conducted in the United States, Canada and Israel on refugee groups that are relatively homogenous as for geographical provenance (Sudan, Eritrea, 
Iraq) as well as religious faith (Christian), several variables appear to be correlated to migrants' processes of psychological adjustment and mental health.

Although laden with expectations of safety and hope, (forced) migrants' arrival in their respective resettlement country engenders delusion and suffering. This sharpens the condition of psychological "exile". Amongst the most frequently noted risk factors during the resettlement phase, there are the lengthiness of juridical asylum procedures, the uncertainty of living conditions, prolonged stays in immigration detention centers (Kronick et al., 2015; Laban et al., 2008); the feeling of being discriminated in the resettlement country due to ethnicity or religion, aggravating the experience of migrants which have already suffered from oppression in their country of origin and injustice; the accumulation of stressful circumstances such as poverty, loss of social roles and status, unemployment, social isolation, identity and culture loss, precariousness of dwelling, discrimination, separation from family members (Betancourt et al., 2015; Ellis et al., 2008; Weine, 2008, 2011).

In addition to the aforementioned stressors, acculturation implicates further difficulties, such as the encounter with a new society and being faced with other cultural models. These experiences cause acculturation stress, intra- and extra-familiar cultural clashes (i.e. couple conflicts, intergenerational acculturative gaps) (Betancourt et al., 2015; Nakash et al., 2015; Yako, Biswas, 2014).

Within the extant research, post-migration stressors and adversities faced by migrants have received considerable attention. However, few studies have considered the role of resilience and protective processes in influencing postmigration adaptation among (forced) migrants and refugees from a salutogenic point of view. According to the Conservation of Resources Theory (COR Betancourt et al., 2015; Hooberman et al., 2010; Silove, 2013), migrant individuals and families face multiple traumatic losses during migration but they are also able to conserve, use and enhance many types of resources (individual, familiar, and collective). According to this framework, the impact of (forced) migration transition is linked to a deeper understanding of the interplay between cumulative pre- and post- resettlement stressors and protective processes on the individual, family and community level (APA, 2010; Bottura, Mancini, 2016; Kramer, Bala, 2010).

Overall, the few quantitative studies conducted on refugee families highlight the presence of positive resources capable of supporting families through this difficult life stage. Resources include family cohesion, community support and the support granted by formal institutions, the relationship with one's country of origin, a parental investment and the stability of children's upbringing (parenting styles, school support, and parental investment), transnational relationships and spiritual beliefs. The stronger one's cultural identity, the 
better such families seem to cope with the difficulties they encounter. On an individual level, religious faith and a strong sense of belonging to a religious community play an important protective role as migrants resettle in new societies. Religious identity is a strong feature of cultural identity and it acts as a spiritual resource as individuals accept and process events (Betancourt et al., 2015; Bottura, Mancini, 2016; Laban et al., 2008; McGregor et al., 2015; Yako, Biswas, 2014).

The wellbeing of younger generations, which experienced (forced) migration, is also strongly linked to some relational resources within their family (cohesion, supportive relationship with parents, parental monitoring, maintenance of cultural and collective identity, effective use of external resources and services) and school (e.g. positive feeling about school, sense of school belonging) (McGregor et al., 2015; Trentacosta et al., 2016).

Within the scenario described above, religion and belonging to a religious community deeply affect migrant people's lives. As previously noted in the present book (Part 1 and Chapter 17), the rebuilding of community and faithbased organizations in their respective resettlement countries has a significant impact on integration processes for religious minorities that have suffered from marginalization and violence in their country of provenance. A body of historical-anthropological as well as sociological literature corroborates this, as it aims at exploring and understanding the experience and history of the so-called migrant Christian Churches, also named Diasporic Churches, well established in several Western countries. ${ }^{1}$

It is worth bearing in mind that within the psychology literature on (forced) migrations reviewed in the present book, for a long time, religion has been exclusively considered as a category to identify pre-migration traumas linked to religion-related persecution. Indeed, few studies have explored the interplay between religion and ethnicity in post-migration identity redefinition process (Eid, 2003; Van Dijk, Botros, 2009). This seeming lack of research is remarkable, especially when considering that transnational religious groups and institutions constitute a resilient resource in supporting members' resettlement and

1 As described in Chapter 18, two terms are used to indicate Egyptian Copt migration, namely "Coptic diaspora", phrase promoted by secular activist Copt organizations in the West, and "Copts/Coptic Churches in the lands of immigration", promoted by the Egyptian Church. The double terminology is symptom of two competing narratives and transnational strategies: the former focuses on human rights and Coptic persecution at the hands of Muslims, the latter focuses on religion and on efforts to persuade Copts to preserve their religious identity in their lands of immigration (Galal, 2012a, 2012b; Haddad, 2013). On the complexity of the concept of diaspora, see also Karoui, 2012. 
acculturation experiences (Bottura, Mancini, 2016; Connor, 2012; Gozdziak, 2002).

As thoroughly illustrated in the first part of the present work, there are several reasons for the limited research interest taken into the variety and diversity of migrant groups' religious experiences, especially regarding Christian (forced) migrants. Psychological research, too, has prevalently described migrant people based on their ethnicity (country of origin). In turn, this has prioritized the focus on ethnic identity whilst blurring other components of identity, thus neglecting the importance of further cultural, religious and language differences amongst migrant groups from the same country. On the contrary, in Western countries, scientific literature and research have looked at religion almost only when the latter is perceived as a problematic issue for how immigrant minorities and the local majority interact in resettlement countries (Sparre, Galal, 2018). As a consequence, in Europe and in other Western countries with a long-standing history of immigration (US, Canada, Australia), attention has mostly been paid to Islam and to integration processes of first- and second-generation immigrant Muslims (Giuliani et al., 2018).

However, over the last decade, it is worth noting that scholars have indeed taken interest in the adjustment process of immigrant Eastern Christian Churches in North America (Canada, US) and in some North-European countries. Next to historical-political perspectives (Chapter 18), studies have been observing the complexity of Middle Eastern Christians' migration experiences to the West, as well as the prominent role played by religious institutions in the lives of their members (Diez, 2017; Marzouki, 2016; Sparre, Galal, 2018).

A recent multi-site fieldwork project conducted in Sweden, Denmark and UK (DIMECCE, 2015; https://arts.st-andrews.ac.uk/dimecce) has explored identity formation processes of three Middle Eastern Christians groups (Iraqi, Assyrian/Syriac, Coptic Orthodox Christians) migrated to European countries and the distinctive traits of their post-migration resettlement experiences. Generally, marginalization and double minority status seem to characterize the experiences of immigrant Middle Eastern Christians in Europe. They are a religious minority in their Muslim-majority country of origin and in their new countries of residence, resulting in their frequently being an invisible minority within a mostly Muslim immigrant group. Galal et al. (2016) suggest that this double minority status is nevertheless displayed in different ways in the three case study countries and that such display is dependent on several factors (specific location, community size, diversity and minority position). In London (UK), where Middle Eastern Christians are one group among others without an apparent majority, they present themselves as a visible minority within a multi-cultural and multi-ethnic setting. In Taastrup (Denmark), Middle 
Eastern Christians are an invisible minority within a visible Arab Muslim immigrant minority. In Södertälje (Sweden), the high concentration of Assyrian/ Syriac Christians living around their churches makes them a visible majority (a "Little Assyria" or "Little Babylon") within an immigrant minority. The diasporic identity of these communities requires careful apprehension of their specific resettlement experiences and relative cultural encounters (Sparre, Galal, 2018).

A few recent studies -mostly carried out in North America- confirm migrant Coptic Churches' will to remain separate and distinct from mainstream society (Van Dijk, Botros, 2009). Said choice seems to be due to both the recent migration history of these communities and to their efforts to retain a strong and distinct ethnic-religious identity in the countries of immigration. Furthermore, these works highlight the prominent role played by migrant Churches and faith-based institutions in preserving a strong connection to the Mother Church and homeland Egypt, replicating religious rituals, negotiating an ethno-religious identity within immigrant societies and supporting adaptation of their members (Botros, 2006; Brinkerhoff, 2009, 2014, 2016; Galal, 2012b; Saad, 2010; Sparre, Galal, 2018; Van Dijk, Botros, 2009; Westbrook, Saad, 2017).

Lastly, a recent quantitative research carried out in United States (Brinkerhoff, 2016) comparing different generations of Coptic immigrants shows that second and third generations are experiencing a selective acculturation pattern, characterized both by a selective retention of their heritage culture and by efforts of positive socioeconomic assimilation in mainstream society. Thus, younger generations' positive assimilation efforts do not seem to prevent the preservation of a strong heritage identity.

Given the extant literature outlined above, and considering the scarcity of psychological studies taking into account Middle Eastern Christian immigrant families' narratives and subjective experiences of migration, the aim of the research illustrated in this chapter has been to explore the post-migration experience of Coptic Orthodox families immigrated from Egypt to Northern Italy, comparing perception and narratives of two different family generations (firstgeneration parents and their second-generation children).

The present study aims to explore post-migration experiences among Coptic Orthodox families immigrated from Egypt to Northern Italy. Specifically, we explored and compared parents and children's narratives about family 
migration history and projects, negotiation processes of their identity within the Italian society, intergenerational transmission of values and practices, role played by religious communities and institutions in their lives, social and community support network.

As previously described (Chapter 18), the Egyptian immigrant community in Italy numbers 119,513 individuals $(67.7 \%$ of them living in Lombardy, a region in Northern Italy) officially residing in Italy on January 1, 2018 (ISTAT, 2018) and it is amongst the largest Muslim minorities in the country. For this immigrant group, the first migration wave was male-dominated. Although this trend was gradually counterbalanced by the arrival of women and children within the scope of family reunification, even today, female Egyptian immigrants in Italy are fewer than male immigrants (33\% versus $67 \%$ ) (ISTAT, 2018). Within the Egyptian immigrant community, it is estimated that the number of Orthodox Copts ranges between 18,000 and 40,000 (https://www.chiesadimilano.it/news/chiesa-diocesi/vivacita-e-fermenti-dei-cristiani-copti-a-milano-146112.html).

From April to June 2017, ten Coptic Orthodox families coming from Egypt participated in the study. Members of Coptic Churches located in Milan suburban area were contacted to inform families about the possibility to take part in the research project and recruit them. For every recruited family, both parents and a preadolescent/adolescent child were interviewed, for a total of 30 interviewed participants: 10 first-generation fathers, 10 first-generation mothers, and 10 second-generation children. Fathers were aged between 37 and $5^{1}$ years $(M=44.9)$ and they had lived in Italy on average for 19.4 years (range: 17-27 y.). Mothers had immigrated to Italy from Egypt through family reunification, were aged between 34 and 43 years $(\mathrm{M}=38.4)$ and had lived in Italy on average for 15 years (range: 9-18 y.). Pre-adolescent and adolescent children ( 5 males, 5 females) were aged between 13 and 16 years $(M=13.5$ ), mostly born in Italy (only 2 had been reunified with their families before they were two) and attending secondary school.

After being informed of the general aim and scope of the research, interested adult participants with their children were invited to sign a consent form and interviewed individually by a researcher with extensive experience in qualitative interviewing and (forced) migration-related topics (Pernice, 1994).

Upon having granted anonymity to participants, the in-depth interviews took place at the respondents' Church. The interview aimed at gauging interviewees' perceptions of the changes occurred in their lives following migration (only for adult respondents), of the challenges and hardships faced in Italy, comparisons between homeland and resettlement country, personal and 
family immigration history, identity construction process, intergenerational communication of values, family relationship and community context (family, school, work, leisure), activities and role of the Coptic Church in their lives.

All interviews were conducted in Italian. Adult and young participants differed in their fluency in the Italian language, with some linguistic difficulties encountered whilst interviewing adult participants.

The interviews were recorded and transcribed verbatim in order to carry out a thematic analysis of the transcripts. Thematic analysis was conducted utilizing Atlas.ti 7.0 (Muhr, 2004); the transcripts were uploaded on the database and subsequently coded independently by two researchers. External team members who were not directly involved with the analysis reviewed the transcripts, methodology and analytic strategy to increase the study's credibility and validity.

\section{$3 \quad$ Results}

The thematic analysis carried out on the interview transcripts has allowed to identify several themes, revealing the complexity that characterizes Coptic families' post-migration experience in Italy. The choice to interview first generation parents and children from the same family has allowed to highlight parallelisms and similarities emerging from their stories.

Firstly, the separation from the home country because of migration has been a recurring theme amongst interviews conducted with first-generation parents - which have directly experienced the migration journey, unlike their children. Although they migrated many years ago, separation from the country of origin and the feeling of estrangement upon arriving in Italy is a strong, vivid memory especially for women.

(...) it's that after you've come here with no job, no language (...) no identity (...) you are very very painful because one is not recognized like, like in Egypt (...) and maybe this is something we all suffer without distinctions, without one taking the skin off ... language ... look, waving hello in the street, what can you say? All these ... without ... naked. (Mother 1)

In the long run, the disorientation experienced upon arrival is coupled with the difficulties and stressful conditions caused by the encounter with another culture and by the acculturation process. Interviewed parents mostly recall the challenging redefinition of gender roles. This has shown both forms of defensive closure towards the new environment to preserve heritage culture (mostly for men) and bi-cultural approaches striving to combine heritage culture and 
new culture (mostly from women). The starkest perceived difference with the new culture concerns the deeply cultural range of gender roles identity within family and society - strict and traditional gender roles can clash with Western, more egalitarian gender roles definition within families.

Most things I cannot, I don't understand because the culture is different (...) Let's say, if before there was something they shouldn't do because it is not possible for females to do this, that ... like in Egyptian culture. (...) For me, all this I still cannot accept because it is an evil thing. (Mother 2)

I, like before, haven't changed anything ... Everything is the same ... same, even though the society was new to me, the culture was new but I have stayed like I was born until now. (Father 1)

I like it as, as a way of living in general, let's say ... as I said earlier Egyptitalian. I take the good from this and the good from that, too, I cannot be pure Italian and pure Egyptian, too (...) now, I am a bit stronger, I manage to do many things, let's say because it's a mum responsible of a house and children. I have to make decisions about many things. This has changed, it wasn't like this before, I was not like this. But now I've become like this, I want to choose, to think things through. (Mother 3)

Memories of pre-migration experiences come to live in both parents and children's stories - although they have never lived in Egypt, children speak about marginalization of and discrimination against their parents in several areas of Egyptian social life, especially the work environment (see also Chapter 20). If, on the one hand, the choice to migrate is linked to a need and a desire for personal and professional emancipation, on the other hand migrant people's high-profile education background was seemingly not adequately matched by the work environment upon arrival. Thus, comparison with the Muslim majority in Egypt is mostly explicitly recalled in terms of discrimination.

Well, my father was like a lawyer in Egypt, but he was Christian anyway, so when compared with Muslim lawyers ... it was more likely that they would hire them instead of him and so ... he came here essentially for work, then essentially from what I remember he started working at a restaurant first, then at a garage and in places like this, then he opened a cleaning company and now he goes, well he works with ... he has a van with which he works with those who make advertisements. (Son 7) 
Look, there are many reasons in Egypt, for us even finding a job is too difficult, as us, as Christians, even in the middle of Egypt, too much effort. (Father 4)

About every aspect of life, even when you are to go to the hospital, when you are at the hospital, all folks are the same, no? No, instead, it's not like that in Egypt for them. (Mother 9)

Episodes of violence against Christians remain in the background. Only two of the men interviewed address it very carefully and prudently; as they recall, episodes happened in the distant past, they mention the Christians' centurieslong martyrdom in Egypt. As far as discrimination is concerned, the comparison with the Muslim majority is explicit, whereas as far as religion-based persecution against Christians is concerned, the theme is treated with greater prudence and awareness of the situation in Egyptian society - mentioning violence suffered by Christians does not imply that Islam or Muslims are generally enemies, but it refers to extremists or jihadists.

The Churches of Egypt have paid with so much blood, since the early days up to now. (Father 2)

In the old generations, grandfathers of grandfathers of grandfathers, we come from a city, from a town where everybody was Christian and half of them were killed. And others fled and others have been killed because they were Christians ... (...) This is something like they have killed more than 3,000 people just because they were Christians, and we're talking about 350 years ago. (Father 1 )

I have experienced them. From the beginning of the 1980 s until 1986 - I have seen my brother jumping from the second floor, running away from jihadists who wanted to kill him because somehow at the time he had let his beard grow, and let his hair grow longer. They said: "You look like your Christ in movies", so they had to kill him. Jumping off, he broke his leg, but other friends brought him to the station and managed to escape. (Father 1)

There have also been terrible moments, in 1997 here in Italy, I heard of my 27 years old brother killed whilst he was praying in church with groups of young people, reciting the vespers, it was Wednesday 12 th February, an extremist had gone to the church and made all these young people die as they were praying ... my brother was the leader of the group and I went back to Egypt to be close to my family until this bad moment went away, but we 
consider him as a martyr because we was dead only for this reason, nothing else, then my family mourned a little, but faith grows anyway. (Father 1)

More than religion-based persecution, the theme of martyrdom is recurring amongst interviewed adults, both mothers and fathers. Telling dramatic events about Christians' persecution asserts one's faith's strength and courage and strengthens the feeling of belonging to the millenary history of the Coptic community, scattered with martyrdoms. As they speak of Christians who were killed in Egypt, interviewed mothers claim and repeat together that "No one is afraid to die" - martyrdom is "not a bad thing"; rather, it is a destiny, evidence and message of faith.

Interviewer: but maybe it is harder to be religious when ...

No, no, no, that is not the case because even when it happened on Palm Sunday ... even after Holy Week there were even more people, for example inside a church there were 3,00o people, there were even 5,00o people inside. They go more often, they go to church even if something happens, my brother. No, no, no, no one is afraid of that.

Interviewer: One needs to be strong, when these things happen

Eh, yes it is not a problem at all, on the contrary, they say next time we all go to church, we must be martyrs ourselves ... even the Gospel that is always in church and this, no one, no one is afraid to die. (Mother 5 )

No one is afraid to die, that also becomes martyr because it is not a bad thing. Because all these martyrs is not (...) prayer because ... we are close to them ... yes but, I'm saying that we are also happy, we are not that afraid ... this never happens. (Mother 8)

Martyrdom conveys the same spiritual strength that animates Coptic migration (according to others, Diaspora) and thus the destiny of all migrants and immigrant Coptic Egyptian families. Migration and all its related suffering find a meaning in being testimony to faith, in serving Christ and in the mission for others. "That's why they are scattered" claims a woman, valuing migration as a choice at once of sorrow and glory - "our pain is our glory". Interviewees' narratives confirm and make apparent that attributing spiritual meaning to one's suffering is amongst the most effective and positive resilience strategies to cope with persecutions (Betancourt et al., 2015; Laban et al., 2008; McGregor et al., 2015; Yako, Biswas, 2014).

I had to leave family behind to go to a place where you don't know where you're going to stay, what to eat, but this is why there is faith within us, 
that we serve Christ this is why there is not fear to go far away and serve like this, my family gave me the courage to serve like this ... (Father 1)

(being Coptic) is the most beautiful thing in the world even if suffering is a part of our glory as a Church. This is our core teaching. The martyrs of the Coptic Church and the suffering in the Middle East, the whole Church, especially us because the Christian majority in the Middle East has taught me our bishop, he has always taught me that our pain is our glory ... this is part of their cross also for us. If you are Christian in Egypt, you are not Muslim, this has been our identity and this to nurture oneself. (Mother 2)

Coptic means that the Coptic Church has always ... been persecuted, it has ... they have offered to their sons, as martyrs do, so I'm happy ... uhm ... I'm Coptic, uhm ... and so our Church ... let's say ...we were few in our country ... (Father 5)

Like the presence of the Lord in Egypt and Christians in Egypt keep on until the last day on Earth and they proclaim his presence here, (...) They are scattered because of this, because it is a very honorable thing ... not for us to be the only ones to keep his Kingdom, we need to give it for others, too (...). None of us wanted to leave Egypt because it is the most beautiful country in the world for us, but with all these bombs, with all these martyrs he has urged of us to go and bring the mission to others. (Mother 1)

As far as identity is concerned, and especially when comparing themselves to Italians, the deep spirituality and the belonging to the Coptic Community are central elements. Comparison with Italian peers -and with the Italian society more generally- emerges from interviews conducted with second-generation children. Such a comparison is instrumental to claim the positive in-group's distinctiveness related to spirituality and assiduous religious practice in a largely non-religious context.

(Being a member of an Egyptian Coptic family) is something that surely makes us different from the others ... because everyone is used to one way of living, whilst I am used to a very different one. Nowadays, I see that the religious sphere shrinks in Italian families, whereas it grows a lot in Egyptian families where it is always increasing because of the persecutions, the suffering, and the suffering of Christians worldwide and most of all in the Middle East and in the East and most of all in Egypt. (Son 1 ) 
Very few Italians go to church ... some (of their Italian peers) are Christians and they have no faith at all, they are Christians, but they do not even believe in Jesus ... (Daughter 6)

Those are not duties, because we love the Church ... (...) yes, it is part of my identity, something specific of our life and Church, Mass, and prayer always! (Mother 6)

I wanted to say that the most important thing about Egypt is that people are more attached to the Church here than in Italy. (Father 1)

Interviews show the efforts of parents and religious institutions to pass down values, practices and religious beliefs to young generations. The aim of such an intergenerational communication of values is twofold: firstly, it aims at granting adults' continuity of individual churchgoing experiences; secondly, it aims at ensuring obedience to what is preached by the Mother Church to diasporic Churches. The relationship with homeland Egypt and Mother Church is very deeply-rooted - indeed, religious identity references and features an ethnic dimension acting as a strong bond with homeland Egypt.

No, faith hasn't changed our Church, here it is the same as the one in Egypt, nothing changes. Even there, all my life I was like him (points at her son) always at church and always at Catechism with parents always for us. (Mother 1)

We are Christians, we have been used to it since we were born, we are always in church and do a lot of things we grew up like this and then I want that my children, too, grow up like we have lived, always growing up here in church and become children of God, not children of the world, that is what we want to be, children of God. (Mother 1)

Because most of all my dad and my mum are very devoted to the Church, to Christianity, they never let I go, my dad always prays for anything and most of all my dad, and my mum a bit less, she's very Christian compared to me and my sister and even for the little things for example, the computer breaks and instead of calling she prays and it's all good, then she calls the technician who fixes it in no time then Mass everyday my dad my mum sometimes after she's taken me to school then she goes, too, otherwise she stays home and is the housewife. (Son 1)

My parents even at catechism they always tell me, when you don't manage to do something ... let's make an example, during a school test, you 
know that you have studied a lot, say that you've been studying that book for three hours, to pass the History test and then you can't remember anything and then you recall the teaching of your parents at catechism and you make the sign of the cross and maybe then you calm down, you trust in Jesus and then maybe you can also hope that the school test goes well. (Son 2)

For both children and parents, praying, rites and activities at the Coptic Church in Italy are crucial.

Faith is fundamental in my life, everything I do is related to faith ... during the day there is Mass, a specific prayer, and I attend it every day and every week I go to the Sunday Mass and on Saturday, too, on Saturday morning, then there are the afternoon prayers and the vespers at night which I always attend ... (Son 1$)$

Religious structures and Coptic communities in Italy greatly support and strengthen religious identity. Regarding the post-migration experience, interviewed families acknowledge the centrality of attachment and the role played by Churches in countries of immigration. Coptic Churches support believers in several ways, ranging from providing religious support, to social, affective, material support, too.

No one manages to live here in Milan without the Church, because the Church is just too important ... important to live, to pray, to meet someone who is a priest and maybe confess, the chance also to be in church that is a quiet place, far away from life, from the stress of the outside world and so church is simply too beautiful a moment. (Mother 5)

No, I can't see the difference. Here the Church does everything ... all Masses, the Holy Week, Christmas, Easter, everything, everything ... in summer they have camps, maybe, they do something that ... the church is always open to everyone. (Mother 5 )

The Churches and those who work for them (priests, bishops, and metropolitans) are a guide and a fundamental point of reference for families coping with an outside world perceived as "threatening" and "negative". Interestingly, interviewed children born here acknowledge said role as guides to navigate a threatening and dangerous world, thus showing a great degree of similarity between how parents and children perceive the world. 
I have learned a lot ...sharing other things than games, experiences and fun. (...) I mean, they teach you a lot about how to behave outside, when somebody is unkind to you, I mean from the lives of Saints you learn how to react outside. (...) Well since I pray and since all the friends I have, I have been knowing them since I was a child, let's say that it's a second family. (Son 2)

The outside world is also ugly, boys outside, what happens in schools. I think I gave everything, the right path and the wrong path. So, the Church is always important (...) that children are born like my son, young, so young until they marry her inside the church (...) otherwise even children outside get lost. I mean, the Church is our mum, a mother ... which is also our very own mum. (Mother 5 )

(...) so about friendships only at church, there is not friendship at school ... girls have many friends they attend catechism together and afterwards they play together, there is quite a few friends, the churches for us I cannot live without churches. (Father 3)

Priests, bishops and metropolitans participate in families' daily and extraordinary decision-making, striving to concretely help families but also, seemingly, to underline their distance from the external society and its institutions (school and young people's gathering places).

For Coptic people, the priest is a very important figure, then always rely on this priest when they don't know where to come, for me with my community there are always meet-ups, when they have problems they call me, always some ... and ...strength ... joy to gather together. (Father 1)

We followed advice from metropolitan A. who even before becoming priest, for us he was always a father, a father for everything, and he tried to give the right advice, put people on the right path and, I mean, has always passed on that who does good, finds good, a right path is always right, so, I mean ... we have, we have that he has pointed in the right direction, so let's hope that we did very few mistakes, or almost none at all. (Father 5 )

I have to answer all, all questions. I am not used to it and I find difficult. The Church has helped me with this. When I cannot answer certain questions, fathers, the Church and the bishops ... because we have a wonderful bishop, really like a father. He lives with us the difficulties that I 
find with my children ... well ... M., my daughter, in her 5 th year of primary school she wanted to go on a school trip for three days. It was the first time because her school usually doesn't bring children to nature camps and I have said, worried: "No M.". Mad, she said "How? Why? All my classmates go apart from me why?" Because I was not used to go on school trips. In Egypt, even at school, boys and girls were apart. Here not, boys sleep ... and I have said no M., and she got mad. I've spoken with our bishop and he said: "Alright, I solve this problem". He called M. and said: "M., we are spending three days in Venice, are you coming with us?" (laughter). (Mother 7)

\section{$4 \quad$ Conclusions}

The aim of this study was to explore migration experiences of Coptic Egyptian families migrated to Italy and living around Milan. More specifically, the study aimed at understanding the families' efforts and resources in the context of both their pre-migration experience as a religious minority in their country of origin and of their encounter with a new culture. Adopting the family-based scope whilst designing the study has allowed to explore processes of adjustment and identity redefinition by combining the voices of several members from the same family - namely, first-generation parents and second-generation children. The 10 families interviewed for the present study belong to and regularly attend Coptic Churches located in Milan's suburban area.

Since the earliest stages of research, including the reaching out phase and the recruitment phase, participants showed a strong ethnic-religious identity, corroborating previous studies (Van Dijk, Botros, 2009); the reaching out phase and the first point of contact was mediated and supervised by the local Coptic Church's priest and all interviews took place at the church the families regularly go to. Therefore, the results allowed us to deepen the understanding of the experience of a group of families that share a strong ecclesial belonging as well as a keen involvement in the activities promoted by their Church. Given the potential bias in our sampling processes, we cannot know the extent to which these findings may be generalized to other Egyptian Coptic immigrants living in Italy.

Parent and children's narrations feature several common elements, and this seems to validate the joint efforts of first-generation parents and religious leaders to pass heritage values and practices onto younger generations (Botros, 2006; Saad, 2010; Saad, Westbrook, 2015). 
A strong sense of belonging to the religious community and a deep, rooted link with the Mother Church and country of origin characterize the experience of interviewed Coptic families. Interviews have highlighted the allencompassing reach of the decision to migrate for men and of family reunification processes for women. The feeling of estrangement experienced upon arrival and the grieving loss of one's homeland are extremely vivid. From the interviews, it emerges that religious identity is strongly connected to an ethnic nuance of the link with the country of origin and with the Mother Church in Egypt (see Chapter 18). The interviews also express the efforts and fatigues brought about by the acculturation process, by the perception of cultural differences - unreconcilable, for some- and by feeling threatened and endangered by the outside world.

The cultural encounter with the Other recurring across the interviews designates only the encounter with "Italians". Interactions with Italian people often acquire negative connotations, because Italian society is essentially considered non-religious and distant from faith. Such difference with the Italian majority underscores the religious and spiritual distinctiveness of the group one belongs to. It also underlines the distinctive features of the Coptic Church since its formation and its mission for Christianity.

The focus on difference -both religious and ethnic- acts as an intergenerational social glue and it is present in parents and children's perceptions of reality and worldviews. Said focus is also the target of great efforts on the part of the parents and the Church to pass on religious faith, to preserve practices and rituals, to maintain a strong link with the Mother Church, in Egypt.

All interviewees (both adolescents and adults) are very proud of the heritage of which they bear witness to the world, as well as about the sorrow and "glory" awaiting Coptic Churches and their believers.

Interviewed individuals -including the second-generation children born in Italy- talk about the difficult situation of Christians in Egypt, where they are marginalized and widely discriminated against by the Muslim majority. Although they do denounce discriminatory behaviors against Christians, interviewees do not talk at length about the acts of violence against Christians in Egypt, nor about Egypt's socio-political situation.

Overall, they do not seem willing to endorse narratives framing them as victims. There is no place for fear, be it fear of the Other, fear of suffering or fear of the disintegration of the community. Although one could see a shared psychological mechanism of denial of reality at work, but the latter should not be regarded as dysfunctional. Indeed, Terror Management Theory (Greenberg et al., 1997) points at the stronger adhesion to one's own cultural worldviews as one 
of the most effective strategies -for individuals and groups- when facing death. Attachment to one's cultural roots and history allows to develop and maintain feelings of symbolic immortality, which counter anxieties and sorrows derived from one's mortality.

Furthermore, interviewees distance themselves from stereotypical representations of Islam as an enemy and of Muslim people as terrorists. Thus, they appear -consciously or unconsciously- to reject the demonizing narratives that are so common in Western countries and illustrated in the introductory part (Chapter 2). For interviewees, the religious theme of martyrdom (in Egypt) and of the migration/diaspora (in Italy) characterize the millenary history of the Coptic Church and as the migration mandate much more decidedly than the theme of violence and persecution against Christians. By praying, interviewees take part in dramatic events unfolding in Egypt, too.

Themes emerged from the interviews are in line with the collective memory and the ethnic-religious identity promoted by the Coptic Orthodox Church on the transnational level (Botros, 2006; Galal, 2012b). As previously noted, the aims and language of such narrative contrast with the narrative promoted by secular Coptic Organizations in immigrant societies (Galal, 2012b; Van Dijk, Botros, 2009). Within the Coptic Churches' narrative, immigrant communities are communities of memory which ensure continuity between the past and the present (Botros, 2006). As highlighted in Chapter 18, several elements from this Coptic narrative are meant to underline the uniqueness and distinctiveness of Coptic communities as regards the outside society; these include the Pharaonic heritage, the twenty centuries of Christianity, the apostolic foundation in Egypt and the glorious early era, up to the latest 14 centuries, which show this Church's resilience, its strength and spirituality, as well as the "miracle of survival". Interviews with parents and children seem to suggest that migration strengthens the celebration of the group's distinctiveness. The theme of migration as a destiny and as a mission conveys the strong link between immigrant Churches and the Mother Church in Egypt, as well as the transnational role of the Mother Church in supporting and guiding immigrant Churches.

In this regard, interviewees greatly value the role played by the community's religious leaders, as they become very dependable in many respects. This applies to migrant parents as well as to young generations, which fulfil their spiritual, material, friendship- and school-related needs within the religious community.

At the same time, interviewees treated the stories of violence against Christians and the issue of relationships between Muslims and Copts in Egypt with great caution. It seems to echo the Mother Church's message and warning to 
avoid issues that may have an impact on Egyptian society, on relationships between Egyptian Muslims and Christians living in Egypt, as such issues run the risk of easing foreign influence into Egypt's socio-political scenario.

Numerous psychology studies have widely emphasized how the intergenerational transmission of a strong ethnic-religious identity is a key protection factor for migrants who often experience distress and fatigue due to immigration (discrimination, status loss, social isolation). Thus, the focus on the history of the Egyptian Coptic Church and its distinctive traits meet the needs of immigrant communities living in Western countries where they face marginalization (Van Dijk, Botros, 2009). However, the emphasis on the distinctiveness of the Coptic identity raises doubts and questions the risks that could arise from such a stark juxtaposition to -and separation from- Italian people and the Italian society as stereotyped in the interviews. The Coptic minority is often an invisible minority within the resettlement country's society (Galal et al., 2016); consequently, choosing to remain separate from it does not seem to promote cultural contacts with the local majority and its communities (Christians, other immigrant communities). In the long run, the gap may become challenging especially for younger generations born and raised in Italy, as they are expected to be loyal to a migration mandate requiring them to protect and preserve their cultural and religious heritage, prioritizing the latter over an opening towards the new culture. Indeed, a strong commitment to the values passed down from their parents and the Coptic community is a strong protection factor. It is nevertheless worth questioning whether this tendency leaves space for intergenerational negotiation, if the choices of the younger generations deviate from prescribed norms and rules. Furthermore, even if younger generations fully endorse the cultural and familial value system, the relationship with the outside world based mainly on defensive or utilitarian behaviors would be problematic. It is a common bias across immigrant communities to underscore their distinctiveness and positive uniqueness compared to the new context they live in. The main issue concerns the extent to which the Coptic Community intend to maintain this separated acculturative orientation or to pursue a more integrative perspective, enabling their members to be open to the new society and culture, while maintaining their cultural roots (Berry, 1997; Phinney et al., 2001) On the long run, integration is widely recognized as the better solution for immigrants and host society in terms of personal and social wellbeing. However, in order to achieve this goal, both the Coptic community and the Italian society need to accept the challenge of trespassing the borders they live in and dare to start interacting with each other. The shared Christian faith may help bridge the gap, allowing for mediation and personal contacts. 
In line with the prospect of an ethics of hospitality presented in the first part of the present work (Chapter 2), the experiences of the Coptic families interviewed corroborates the crucial role of religion in the post-migration phase, as well as the complexity of (forced) migrants' identity redefinition process.

The religious sphere is intrinsically connected to the history of this community and to the collective memory passed down from one generation to the next. However, the religious sphere necessarily faces the challenges derived from the narratives and counter-narratives that inform the Western gaze on migrants, refugees and asylum seekers. In our study, interviewed families' difficulties with the encounter with the Other is conveyed through the perception of the outside world as threatening, a world one needs to be cautious of; yet, at the same time, it is a world in which it is possible to reaffirm the distinctiveness and strength of one's Church. The risk of an introverted tendency and of displaying reactive solutions and behaviors is apparent. As such behaviors risk creating an extreme gap between immigrant communities and the Italian society, they make it more complicated to individuate the common good that human migration can promote. 